\title{
LEVELS AND DIFFERENTIALS IN CHILDHOOD MORTALITY IN SOUTH AFRICA, 1977-1998
}

\author{
NADINE NANNAN*, IAN M. TIMÆUS $\uparrow$, RIA LAUBSCHER $†$ AND \\ DEBBIE BRADSHAW*
}

\begin{abstract}
*Burden of Disease Research Unit, South Africa Medical Research Council, South Africa, $\dagger$ Centre for Population Studies, London School of Hygiene \& Tropical Medicine, London, UK and \$Biostatistics Unit, South Africa Medical Research Council, South Africa
\end{abstract}

\begin{abstract}
Summary. This study uses the 1996 Census and the 1998 Demographic and Health Survey (DHS) to investigate the level of and trend in infant and child mortality and their covariates in South Africa. Census estimates of childhood mortality are higher than those from the DHS. Analysis suggests that the former overestimate mortality while the latter are probably slightly too low. Both inquiries document a reversal of the trend toward lower mortality in the 1990s. Under-five mortality increased by about a third during the five years up to early 1998. By then the infant mortality rate was about 55 per 1000 and under-five mortality 72 per 1000 . Other factors may explain the tapering off of the decline in mortality after the late 1980s but AIDS deaths account for its increase. Inequalities in childhood mortality between population groups, rooted in past discriminatory apartheid policies, shrank between the late1970s and mid-1990s. However, they remain substantial and are largely unaccounted for by province, metropolitan residence and inter-group differences in mothers' education. The HIV/AIDS epidemic is likely to offset the beneficial impact of post-apartheid pro-poor policies and may exacerbate racial differences in childhood mortality in South Africa. There is an urgent need to improve the routine collection of statistics to monitor child mortality so as to assess progress towards the Millennium Development Goals and track inequalities.
\end{abstract}

\section{Introduction}

Until 1994 South Africa was characterized by a system of institutionalized racism, apartheid. Apartheid policies divided the population into legally defined racial groups and discriminated between them in all spheres of life: health, education, occupational opportunities, income and the areas in which people could live and work. For 
example, in 1991 black (i.e. non-White) men - who constituted 77\% of the male labour force in the Republic of South Africa (RSA) - earned on average only 19\% as much as White men (Treiman et al., 1996). Moreover, legal differences in status within the black population led to differential socioeconomic opportunities which left, in general, Indians better off than Coloureds, and the Coloured population better off than Africans. (In this paper we follow contemporary South African usage and use the term 'African' to refer to the group who were legally defined as 'Black' by apartheid legislation. Population group is now a self-reported ethnic identity in South Africa).

The first general election with universal suffrage was held in 1994, marking the transition to democracy. However, it is likely that the gross socioeconomic inequalities that are the legacy of apartheid will characterize South African society for years to come (Terreblanche, 2003). Thus, although South Africa is a middle-income country, about half the population live in poverty and most of the poor are Africans (Statistics South Africa, 2000). Racial differences in socioeconomic status have narrowed somewhat with the relaxation and then abolition of apartheid policies and practices since the 1980s. Nevertheless, South Africa still had a Gini coefficient of 0.69 in 2000, making it the third most unequal country in the world (United Nations Development Program, 2001).

The complex pattern of racially related social disadvantage found in South Africa produces steep gradients in mortality rates (Wyndham, 1981) and health status (World Health Organization, 1983; Bradshaw \& Nannan, 2004) across the different population groups. Moreover, these socioeconomic and health inequalities have a spatial as well as a racial dimension. During the apartheid era, the Republic of South Africa was viewed as home to the White population and only those sections of the African majority with the appropriate permits were entitled to reside or work in South Africa 'proper'. Other Africans could live only in their designated 'independent' (Transkei, Boputhatswana, Venda and Ciskei) or 'self-governing' (Lebowa, KwaZulu, QwaQwa, KaNgwane, Gazankulu and KwaNdebele) 'homeland'.

In addition to inequalities in income and wealth, the South African population of some 46 million is characterized by tremendous cultural diversity. The country has eleven official languages. The aboriginal Khoisan occupied southern Africa for centuries until Bantu-speaking peoples began to migrate into the region around 300-500 AD, with Nguni-speaking peoples eventually settling in the eastern part of the region and Sotho-speakers settling to their west and in the north. European explorers first established an outpost in the Cape in 1652 to provide provisions for the passing sea trade and gradually expanded across the rest of the country. The racial grouping referred to as 'Coloured' in apartheid legislation are the descendants of south-east Asian slaves who were brought to the Cape Colony and of the offspring of people from different groups. Many of the Indian population descend from indentured labourers brought to South Africa in the nineteenth century to work on the sugar plantations on the eastern coast. In 1996 the census included a question on self-reported population group and the responses were: African (77\%), White (11\%), Coloured (9\%), Asian/Indian (3\%) and Other (1\%).

Studies of childhood mortality in South Africa using vital statistics have been restricted severely by very incomplete registration of both births and deaths of young 
children (Botha \& Bradshaw, 1985; Nannan et al., 1998). Hence, the main source of information on the trends in infant and child mortality prior to the abolition of the apartheid system is the series of surveys modelled on those in the Demographic and Health Surveys programme that was carried out by the Human Sciences Research Council (HSRC) between 1987 and 1992 (Roussouw \& Hofmeyr, 1990). These surveys document declines in child mortality rates for all population groups, though the greatest reductions are among Asian, Coloured and White children. In accordance with the pattern of racial discrimination in the country, infant mortality rates in the early 1980s were estimated at 13, 20, 57 and 68 per 1000 live births for White, Asian, Coloured and African children respectively. Other important determinants of child mortality included province and urban/rural residence (Roussow \& Jordaan, 1997).

At the very end of the apartheid era, nationally representative information on the population was collected by the 1993 Living Standards and Development Survey, sponsored by the World Bank and also known as the Poverty Survey. Estimates of childhood mortality from this dataset are higher than those from other surveys, but confirm that mortality was falling in the 1980 s and reveal a pattern of socioeconomic differentials in mortality like that in other developing countries (Mazur, 1995). The other studies conducted in the 1980s and early 1990s that investigated differentials in childhood mortality were smaller and focused on sub-populations, exploring the variation in infant mortality rates by race and geographical area within a province (Yach, 1988; Bachmann et al., 1996), or looking at the variation in infant mortality for a particular racial group according to a range of socioeconomic variables (Pick et al., 1996). None of these analyses calculated the net impact of each of the major determinants of childhood mortality adjusting for the effects of other variables.

Reducing the ubiquitous inequalities in South African society has been one of central objectives of the new government's policies. Reintegration of the 'homelands' into South Africa and major programmes to improve housing conditions and provide access to clean water, electricity and other basic services might be expected to reduce infant and child mortality. However, such programmes take time to benefit large numbers of people and, in the short term, the process of restructuring undoubtedly disrupted the administration and delivery of government services. Moreover, the period up to 1998 also saw large increases in unemployment in South Africa. On the other hand, enhancement of the state pension provided an important boost to the income of many poor households, including those containing young children (Case \& Deaton, 1998). The size and direction of the impact on infant and child mortality of the massive economic and social changes that occurred in South Africa in the 1990s is not immediately clear.

Unfortunately, one development in South Africa in the 1990s undoubtedly had a large adverse impact on childhood mortality - the rapid spread of HIV/AIDS. Perhaps because it was protected in part by its international isolation under apartheid, the HIV epidemic arrived late in South Africa. In 1990 the prevalence of HIV infection among pregnant women seen in government antenatal clinics was just $0 \cdot 8 \%$. By 1994 it had reached 7.6\% and by October 1998 was 22.8\% (Department of Health South Africa, 2005). The government only began to pilot programmes for the prevention of mother-to-child transmission in 2000. During the 1990s, therefore, about one-third of these women will have transmitted HIV to their children and the 
majority of these children will have developed AIDS and died before their fifth birthday.

Improving child survival is one of the eight Millennium Development Goals (United Nations, 2000) and infant and child mortality are key measures of a country's health that it is crucial to monitor. The 1996 Census and the 1998 Demographic and Health Survey (DHS) were the first nationally representative inquiries conducted under the auspices of the new government that collected useful data on childhood mortality. It has proved impossible to produce estimates of childhood mortality from the 2001 Census data because children ever-born and surviving were not reported or implausible responses were recorded for very large numbers of women (Dorrington et al., 2004). Therefore, the two inquiries in the 1990s still provide the only useful data available on post-apartheid South Africa as a whole. Burgard \& Treiman's recent (2006) analysis compares differentials in childhood mortality according to the 1998 DHS with those documented by the HSRC surveys conducted a decade earlier. This paper has largely complementary objectives. It describes trends in under-five mortality in South Africa since the late 1970s in more detail. It investigates the reasons for the discrepancies between estimates of childhood mortality made from the 1998 DHS and 1996 Census and proposes appropriate adjustments. Third, it assesses geographical as well as inter-group and socioeconomic inequalities in childhood mortality in conjunction with each other and identifies the net size of the differentials associated with each factor.

\section{Data and Methods}

\section{Data sources}

The 1996 Census was the first since 1970 to attempt to enumerate all South Africans. The designated 'homelands' and 'self-governing territories' and the Republic of South Africa were again incorporated into one inquiry designed to provide population statistics for the nine newly demarcated provinces. The Census asked just over 9 million women of reproductive age simple questions about how many children they had given birth to and how many of these children were still alive. The 1998 DHS used a two-stage cluster sampling design to draw a nationally representative sample of 11,735 women aged 15-49 years. It collected detailed pregnancy histories from these women that include the dates and outcomes of each of their pregnancies and the ages at death of those live-born children who subsequently died.

\section{Indirect estimates}

The census data on the proportion of children who have died tabulated according to the age of their mother can be used to estimate conventional life-table indices of childhood mortality by means of an indirect method first developed by Brass (Brass \& Coale, 1968). This study uses a variant of this original method (United Nations, 1983). Proportions of those children born alive who have died before the date of the survey by the age of the mother are converted into probabilities of dying by adjusting for the timing of fertility using a set of multipliers determined by the average parities of young women in the first half of their reproductive lives. The probabilities of dying 
Table 1. Indirect estimates of under-five mortality $\left({ }_{5} q_{0}\right), 1996$ Census ${ }^{\mathrm{a}}$

\begin{tabular}{lcccccc}
\hline $\begin{array}{l}\text { Age group } \\
\text { of women }\end{array}$ & $\begin{array}{c}\text { Mean parity Proportion of } \\
\text { of women }\end{array}$ & $\begin{array}{c}\text { Age of } \\
\text { child } \\
(x)\end{array}$ & $\begin{array}{c}\text { Probability of } \\
\text { dying by age } x \\
\left({ }_{x} q_{0}\right)\end{array}$ & $\begin{array}{c}\text { Under-five } \\
\text { mortality } \\
\left({ }_{5} q_{0}\right)\end{array}$ & Date \\
\hline $15-19$ & $0 \cdot 1459$ & $0 \cdot 0863$ & 1 & $0 \cdot 0787$ & $0 \cdot 1042$ & June 1995 \\
$20-24$ & $0 \cdot 6702$ & $0 \cdot 0628$ & 2 & $0 \cdot 0637$ & $0 \cdot 0735$ & March 1994 \\
$25-29$ & $1 \cdot 4226$ & $0 \cdot 0595$ & 3 & $0 \cdot 0596$ & $0 \cdot 0645$ & June 1992 \\
$30-34$ & $2 \cdot 2770$ & $0 \cdot 0672$ & 5 & $0 \cdot 0687$ & $0 \cdot 0687$ & June 1990 \\
$35-39$ & $2 \cdot 9293$ & $0 \cdot 0810$ & 10 & $0 \cdot 0846$ & $0 \cdot 0775$ & April 1988 \\
$40-44$ & $3 \cdot 4429$ & $0 \cdot 0994$ & 15 & $0 \cdot 1027$ & $0 \cdot 0886$ & November 1985 \\
$45-49$ & $3 \cdot 7499$ & $0 \cdot 1180$ & 20 & $0 \cdot 1209$ & 0.0955 & December 1983 \\
\hline
\end{tabular}

aThese data have been adjusted for the miscoding of childless women as parity 'not stated' and misclassification of stillbirths as live births. Under-five mortality is estimated using coefficients based on Coale-Demeny (1983) West life-tables; see text for details.

over various age ranges yielded by data on the children of mothers of different ages are converted into a common index of the probability of a child dying before their fifth birthday ('under-five mortality') using Brass's relational logit system and a standard drawn from the Coale-Demeny West family of model life-tables (Coale et al., 1983).

The El-Badry (1961) correction is used to adjust the data on women's parity for the tendency of the census enumerators to leave the schedule blank for childless women. Because nearly all the women tabulated as 'parity not stated' are in the first few reproductive age groups, it is highly likely that most of them are in fact childless, substantially reducing the mean parities of younger women. This affects the size of the multipliers used to convert of proportions of children dead into life-table indices of mortality.

A second adjustment is used to correct the data for the excess mortality risk of children born to teenage mothers (Collumbien \& Sloggett, 2001). The adjustment requires one to determine the mortality of births to mothers aged less than 20 relative to the risk of dying for other births in order to adjust the mortality estimates for the children of women aged 15-19 and 20-24 downward so that they represent the mortality of all children. Estimates made from the births in the last ten years captured in the DHS birth histories indicate that $5.95 \%$ of births to women aged less than 20 had resulted in death, compared with $5 \cdot 13 \%$ of births to women aged $20-24$, giving a relative risk of $1 \cdot 16$. As $18 \cdot 8 \%$ of all births were borne by women aged less than 20 , the average risk for all births is $0.188 \times 1 \cdot 16+0 \cdot 812=1.03$ of the risk to women aged 20 or more. The proportion dead for the 15-19 year age group was therefore multiplied by a correction factor of $1 \cdot 03 / 1 \cdot 16=0 \cdot 89$. As $56 \%$ of the children of women aged 20-24 were born when they were teenagers, for this age group the correction factor is $1 \cdot 03 / 1 \cdot 09=0 \cdot 94$.

A third adjustment to the number of child deaths is made on the basis of work done by Moultrie \& Timæus (2002, Appendix 2), who argue that the number of child 
deaths reported in the Census is inflated by the misclassification of stillbirths as dead live births. In the DHS pregnancy histories, women reported 14.5 births per 1000 live births where the baby did not show any sign of life. The Census enumeration did not use probes to distinguish between stillbirths and live births and Moultrie \& Timaeus suggest that consequently many such stillbirths were reported as live births that died. This view is supported by the fact that (after correcting the Census data for coding of childless women as parity 'not stated') the numbers of living children reported by the two sources match well (Moultrie \& Timaeus, 2002). Thus, no evidence exists of a general problem with the reporting of lifetime fertility in either source, only of one with the reports on dead children. In addition, the Census question was a complex one, with a final phrase in the second set of parentheses that perhaps offsets the instruction in the first parenthesis:

How many children, if any, has the woman ever given birth to? (live births) (Please include her children who are not living with her and those who have died.)

If one assumes that the propensity to report stillbirths as dead births was as strong in the Census as in the DHS, the number of dead children reported should be adjusted downward by approximately $22 \%$ to allow for misclassification of the outcome of these pregnancies.

\section{Direct estimates}

Period life-table indices of mortality were calculated from the 1998 DHS data for both single years prior to the dates of interview and calendar years by means of the $s t$ commands provided in Stata (Stata Corp, 2005a). These procedures divide deaths and person-years of exposure to the risk of dying between years precisely using exact dates of birth and interview and the ages at death of dead children and calculate KaplanMeier estimates of life-table survivorship. Estimates of under-five mortality made from the 1998 DHS are lower than those made from the 1996 Census but correlate closely with them except in the Western Cape and the Free State, where the mortality observed in the 1998 DHS is relatively low. Different organizations conducted fieldwork for the DHS in each province. An equivalent comparison of these two sets of provincial estimates with those from the 1993 Living Standards and Development Survey suggests that it is the DHS data and not those from the 1996 Census that are out of line in Western Cape and Free State. Moreover, the DHS estimate for Western Cape is implausibly low. Therefore, a linear regression model was fitted to the estimates for the remaining seven provinces that predicts under-five mortality in the DHS from the Census results (after adjusting for the misreporting of stillbirths) and is used to revise the estimates for Western Cape and Free State. This suggests that national estimates of mortality from the 1998 DHS should be raised by a factor of $4.7 \%$ to allow for the underestimation of childhood mortality in these two provinces.

\section{Analysis of differential mortality using Poisson regression}

The data file is structured as an aggregated data file for children born during the 18 years prior to interview of their mother in the 1998 DHS. Each child's exposure 
time from birth until interview or the point of death is divided up by age and then summed across all children sharing a common set of characteristics. Poisson regression is used to fit a regression model to the $\log$ of the rate calculated as the number of deaths divided by exposure time:

$$
\ln \left(d_{i j} / \mathrm{PYO}_{i j}\right)=\ln \left(d_{i j}\right)-\ln \left(\mathrm{PYO}_{i j}\right)=\beta_{0}+\beta_{1} X_{i}+\beta_{2} X_{1 j}+\beta_{3} X_{2 j}+\ldots+\beta_{n+l} X_{n j}
$$

where $d_{i j}$ is the count of deaths and $\mathrm{PYO}_{i j}$ is the person-years of observation for a particular age group $i$ and combination of covariates $j$. Exposure times are incorporated in the model as an 'offset' term. The model was fitted using the svy:poisson command in Stata to take into account the design of the DHS sample (Stata Corp, 2005b).

Ages at death and exposure time are categorized into the following intervals: less than 28 days and 1-2, 3-11, 24-35 and 36-59 months. The demographic and socioeconomic covariates of child mortality considered in the model are: the time trend in mortality across six three-year time periods, South Africa's four population groups (African, Asian, Coloured and White), the child's sex, the nine provinces, metropolitan versus non-metropolitan residence, the mother's education and an interaction term between population group and age.

\section{Results}

Table 1 presents indirect estimates of under-five mortality based on data from the 1996 Census adjusted for the misstatement of parity and the misclassification of stillbirths. Table 2 presents direct estimates of childhood mortality for each of the 21 years preceding the DHS. Figure 1 presents the indirect estimates of under-five mortality based on Census data from Table 1, a series based on the same data that are unadjusted for the misreporting of stillbirths as child deaths, and direct and indirect estimates of the same index from the 1998 DHS. The indirect estimate representing the child mortality of the youngest age group of women (15-19 years) has been omitted from the figure as, even after applying the Collumbien \& Sloggett (2001) adjustment, it seems atypical of the rest of the population. The direct estimates have been smoothed using a three-point moving average. The slightly higher DHS estimates that result if one adjusts for under-reporting of deaths in Western Cape and Free State are shown as well as unadjusted direct estimates. A large and worrying discrepancy exists between the unadjusted results from the 1996 Census and those from the DHS conducted two years later. Averaging over the period 1982 to 1994, the DHS estimates are only two-thirds of those from the Census.

Two factors account for the bulk of this discrepancy. The first is that the DHS distinguished stillbirths from dead live births while the Census included some as infant deaths. The DHS questionnaire contained probing questions to determine whether pregnancies had ended in a stillbirth rather than a dead live birth. The census did not and misclassification of stillbirths as dead live births on the scale that occurred in the DHS before asking the probing questions would account for most of the discrepancy between the two sets of estimates in Figure 1. Second, the indirect estimates made from the DHS data are markedly higher than the directly calculated estimates made from the same basic data. They should be similar. This suggests that the indirect 
Table 2. Direct estimates of childhood mortality by age and year before the survey, 1998 Demographic and Health Survey

\begin{tabular}{lccccc}
\hline $\begin{array}{l}\text { Years before } \\
\text { survey }\end{array}$ & $\begin{array}{c}\text { Neonatal } \\
\text { mortality }\end{array}$ & $\begin{array}{c}\text { Post-neonatal } \\
\text { mortality }\end{array}$ & $\begin{array}{c}\text { Infant mortality } \\
\left({ }_{1} q_{0}\right)\end{array}$ & $\begin{array}{c}\text { Child mortality } \\
\left({ }_{4} q_{1}\right)\end{array}$ & $\begin{array}{c}\text { Under-five mortality } \\
\left({ }_{5} q_{0}\right)\end{array}$ \\
\hline & & & $0 \cdot 0626$ & $0 \cdot 0257$ & $0 \cdot 0867$ \\
0 & $0 \cdot 0199$ & $0 \cdot 0427$ & $0 \cdot 0318$ & $0 \cdot 0099$ & $0 \cdot 0414$ \\
1 & $0 \cdot 0187$ & $0 \cdot 0131$ & $0 \cdot 0633$ & $0 \cdot 0130$ & $0 \cdot 0755$ \\
2 & $0 \cdot 0350$ & $0 \cdot 0283$ & $0 \cdot 0297$ & $0 \cdot 0108$ & $0 \cdot 0402$ \\
3 & $0 \cdot 0143$ & $0 \cdot 0154$ & $0 \cdot 0380$ & $0 \cdot 0099$ & $0 \cdot 0475$ \\
4 & $0 \cdot 0105$ & $0 \cdot 0275$ & $0 \cdot 0433$ & $0 \cdot 0142$ & $0 \cdot 0569$ \\
5 & $0 \cdot 0237$ & $0 \cdot 0196$ & $0 \cdot 0319$ & $0 \cdot 0156$ & $0 \cdot 0470$ \\
6 & $0 \cdot 0159$ & $0 \cdot 0160$ & $0 \cdot 0393$ & $0 \cdot 0135$ & $0 \cdot 0523$ \\
7 & $0 \cdot 0146$ & $0 \cdot 0247$ & $0 \cdot 0449$ & $0 \cdot 0224$ & $0 \cdot 0663$ \\
8 & $0 \cdot 0251$ & $0 \cdot 0198$ & $0 \cdot 0353$ & $0 \cdot 0162$ & $0 \cdot 0509$ \\
9 & $0 \cdot 0136$ & $0 \cdot 0217$ & $0 \cdot 0477$ & $0 \cdot 0172$ & $0 \cdot 0641$ \\
10 & $0 \cdot 0186$ & $0 \cdot 0291$ & $0 \cdot 0568$ & $0 \cdot 0213$ & $0 \cdot 0769$ \\
11 & $0 \cdot 0273$ & $0 \cdot 0295$ & $0 \cdot 0516$ & $0 \cdot 0188$ & $0 \cdot 0694$ \\
12 & $0 \cdot 0252$ & $0 \cdot 0264$ & $0 \cdot 0544$ & $0 \cdot 0226$ & $0 \cdot 0758$ \\
13 & $0 \cdot 0247$ & $0 \cdot 0297$ & $0 \cdot 0433$ & $0 \cdot 0222$ & $0 \cdot 0645$ \\
14 & $0 \cdot 0183$ & $0 \cdot 0250$ & $0 \cdot 0448$ & $0 \cdot 0223$ & $0 \cdot 0661$ \\
15 & $0 \cdot 0161$ & $0 \cdot 0287$ & $0 \cdot 0504$ & $0 \cdot 0186$ & $0 \cdot 0681$ \\
16 & $0 \cdot 0224$ & $0 \cdot 0280$ & $0 \cdot 0621$ & $0 \cdot 0288$ & $0 \cdot 0891$ \\
17 & $0 \cdot 0290$ & $0 \cdot 0331$ & $0 \cdot 0807$ & $0 \cdot 0339$ & $0 \cdot 1119$ \\
18 & $0 \cdot 0272$ & $0 \cdot 0535$ & $0 \cdot 0829$ & $0 \cdot 0309$ & $0 \cdot 1112$ \\
19 & $0 \cdot 0310$ & $0 \cdot 0519$ & $0 \cdot 0831$ & $0 \cdot 0397$ & $0 \cdot 1195$ \\
20 & $0 \cdot 0429$ & $0 \cdot 0402$ & & & \\
\hline & & & & & \\
\hline
\end{tabular}

approach performs poorly in South Africa because the proportions dead are being converted into an under-five mortality rate using assumptions that are inappropriate for this country. The issue of exactly what is going wrong with the indirect estimates is considered in the Discussion section. However, if the method rather than the data are at fault, the Census results are also likely to be biased. Finally, a further but less important factor contributing to the inconsistencies between the Census and DHS is the under-reporting of child deaths in Western Cape and Free State in the DHS. Figure 1 shows that, after allowing for these three factors, the adjusted Census estimates and adjusted indirect estimates from the DHS are very similar. Much of the residual discrepancy probably stems from the fact that the DHS interviewed a slightly more educated and urbanized sample of women than were enumerated in the Census (Moultrie \& Timæus, 2003). Thus, our assessment is that the direct estimates of childhood mortality from the 1998 DHS are probably only slightly too low but that the Census results are biased severely upward both by misreporting of stillbirths as child deaths and by the indirect method used to estimate mortality.

Although they disagree as to the level of childhood mortality, the series of mortality estimates in Figure 1 agree rather well as to the trend in mortality. A substantial decline in under-five mortality occurred in the $1980 \mathrm{~s}$ that petered out in 


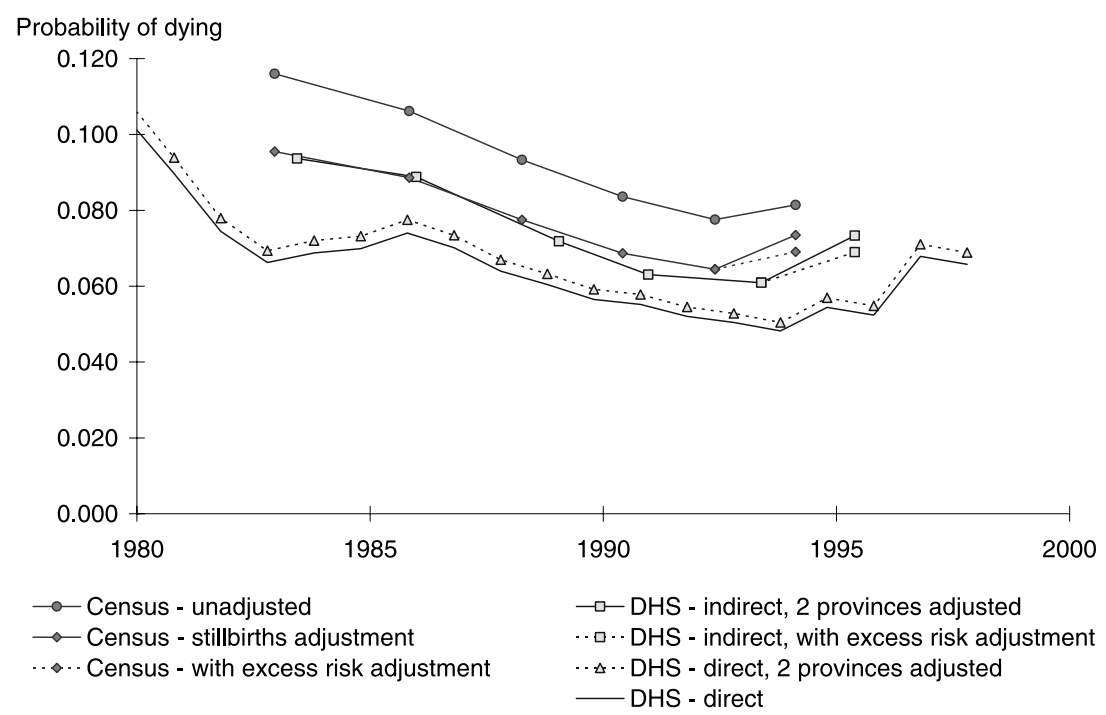

Fig. 1. Under-five mortality according to the 1998 Demographic and Health Survey and 1996 Census.

the early 1990s and was followed by a rise in mortality. The Census as well as the DHS results suggest that mortality rose in the mid-1990s. They do not reveal quite as sharp a rise in mortality as the direct estimates from the DHS conducted two years later. This is to be expected, however, as indirect estimates are based on data on cohorts of children. As is also evident in the indirect results from the DHS shown in Figure 1, this tends to smooth out mortality trends.

Figure 2 presents estimates of childhood mortality by age for calendar years according to the 1998 DHS. Erratic fluctuations in the series have been smoothed out using a five-point Henderson (1916) moving average. Most of the reduction in overall infant mortality in the period 1975 to 1991 is attributable to the decline in the post-neonatal period. Post-neonatal mortality halved between the mid-1970s and mid-1980s and then fell more gradually until the early 1990s. The mortality of neonates fell less steeply, declining by $30 \%$ between the mid-1970s and early 1990s. The pattern of decline in child mortality was similar to that for older infants. Neonatal and post-neonatal mortality began to rise in about 1993 and underwent increases of $31 \%$ and $48 \%$ respectively by early 1998. Child mortality began to increase somewhat later, in about 1995, but had risen by 39\% by early 1998 .

Poisson regression models of the association between demographic and socioeconomic covariates and under-five mortality are shown in Table 3. Results based on the entire DHS sample are presented but the same models have been fitted excluding the data from the Western Cape and the Free State provinces, where it is suspected that childhood mortality was under-reported. This had little effect on conclusions to be drawn about the other covariates. The left-hand column of results examines mortality by age, sex and population group, controlling only for the overall trend in mortality in the country. Both the drop in under-five mortality between the early 


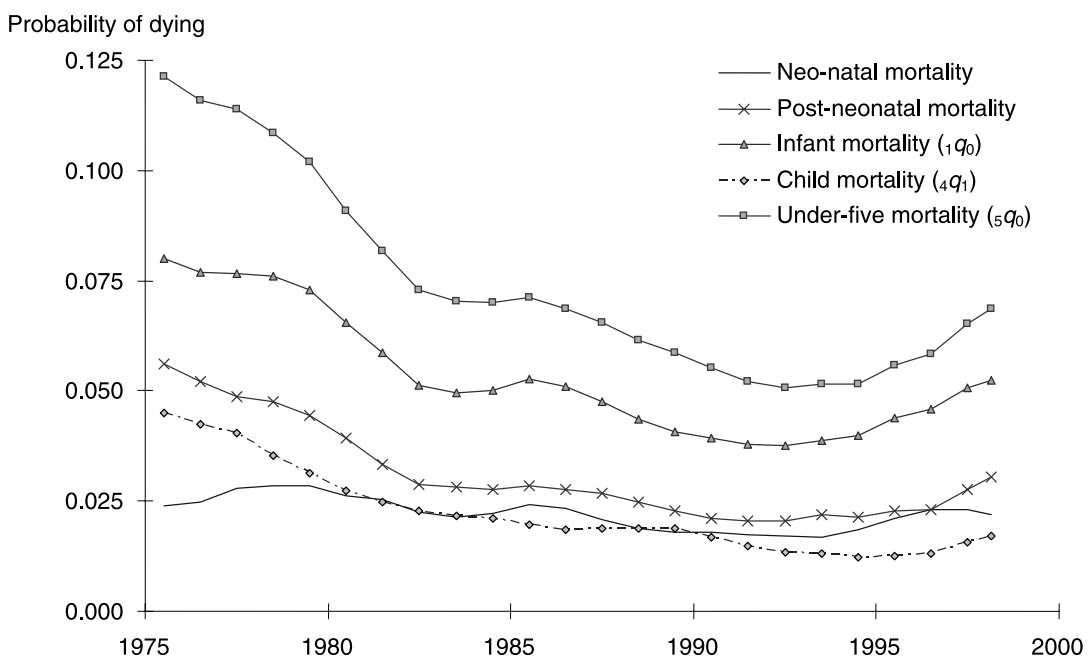

Fig. 2. Direct estimates of childhood mortality by age, 1998 Demographic and Health Survey.

1980s and mid-1990s and the subsequent increase in children's mortality between 1992-5 and 1995-8 are confirmed to be statistically significant. Young girls are about $25 \%$ less likely to die before age 5 than boys.

The first model shows that the age pattern of mortality varies significantly between African children and those from other population groups. The population group and age group interaction term shows that mortality is less concentrated in the neonatal period for African children $(p=0 \cdot 006)$. Table 4 shows estimated relative risks of dying for each population group. The disadvantage of African children is twice as great after the first month of life as it is for neonates: African children have about three times higher mortality than White children in the neonatal period but $6 \cdot 6$ times the mortality of White children and significantly higher mortality than all the other population groups after the first month of life. Coloured children have about $2 \cdot 5$ times the mortality of White children $(p=0 \cdot 025)$ and the White children probably have lower mortality than Asian children as well $(p=0 \cdot 097)$.

The second model in Table 3 explores to what extent differences in mortality by race are explained by the distribution of the racial groups between metropolitan and non-metropolitan areas and the different provinces. After controlling for provincial and racial differences, children living in metropolitan areas have only about $77 \%$ of the mortality of children elsewhere in the country. Provincial mortality experience is measured against the mortality of children in the Eastern Cape - the province with the highest mortality rates. The three eastern provinces - Eastern Cape, KwaZulu Natal and Mpumalanga - all have relatively high mortality. In contrast, Free State, Limpopo, North West and Gauteng provinces share similar but lower mortality levels. Thus, once one allows for the benefits of metropolitan residence and minority group status, childhood mortality seems no worse in the Limpopo and North West, which largely comprise ex-homelands, than in provinces that used to belong mainly to White South Africa. The very low mortality reported for Western Cape is in part 
Table 3. Poisson regression estimates of the relative risk of dying in childhood (and $95 \%$ confidence intervals) according to socioeconomic and demographic covariates, 1998 Demographic and Health Survey

\begin{tabular}{|c|c|c|c|c|}
\hline Covariate & Category & $\begin{array}{l}\text { Model } 1 \\
\text { Age-, race- } \\
\text { and sex- adjusted } \\
\text { risk ratios }\end{array}$ & $\begin{array}{l}\text { Model } 2 \\
\text { Age-, race-, sex- } \\
\text { dand geographically } \\
\text { adjusted risk ratios }\end{array}$ & $\begin{array}{l}\text { Model } 3 \\
\text { Fully-adjusted } \\
\text { risk ratios }\end{array}$ \\
\hline \multirow{6}{*}{$\begin{array}{l}\text { Years before } \\
\text { survey }\end{array}$} & 0-2 (1995-98) & 1 & 1 & 1 \\
\hline & $3-5(1992-95)$ & $0 \cdot 71(0 \cdot 55-0 \cdot 93)$ & $0.72(0.55-0.94)$ & $0.71(0.54-0.92)$ \\
\hline & 6-8 (1989-92) & $0.82(0.62-1 \cdot 09)$ & $0.83(0.62-1 \cdot 10)$ & $0 \cdot 80(0 \cdot 60-1 \cdot 06)$ \\
\hline & 9-11 (1986-89) & $0.96(0 \cdot 75-1 \cdot 24)$ & $0.97(0.76-1 \cdot 26)$ & $0.92(0 \cdot 71-1 \cdot 19)$ \\
\hline & $12-14(1983-86)$ & $1.07(0 \cdot 85-1 \cdot 34)$ & $1 \cdot 08(0 \cdot 87-1 \cdot 35)$ & $1 \cdot 01(0 \cdot 81-1 \cdot 26)$ \\
\hline & 15-17 (1980-83) & $1 \cdot 15(0 \cdot 87-1 \cdot 51)$ & $1 \cdot 16(0 \cdot 89-1 \cdot 53)$ & $1 \cdot 07(0 \cdot 81-1 \cdot 41)$ \\
\hline \multirow[t]{2}{*}{ Sex } & Boys & 1 & 1 & 1 \\
\hline & Girls & $0 \cdot 74(0 \cdot 65-0 \cdot 85)$ & $0.74(0.65-0.84)$ & $0.74(0.65-0.84)$ \\
\hline \multirow[t]{4}{*}{ Population group } & African & 1 & 1 & 1 \\
\hline & Coloured & $0 \cdot 76(0 \cdot 52-1 \cdot 11)$ & $1 \cdot 25(0 \cdot 78-1.99)$ & $1 \cdot 31(0 \cdot 82-2 \cdot 09)$ \\
\hline & Asian & $0 \cdot 71(0 \cdot 35-1 \cdot 44)$ & $0.76(0 \cdot 36-1 \cdot 61)$ & $0.88(0.41-1.85)$ \\
\hline & White & $0.31(0 \cdot 13-0 \cdot 71)$ & $0 \cdot 37(0 \cdot 16-0 \cdot 86)$ & $0 \cdot 50(0 \cdot 21-1 \cdot 15)$ \\
\hline \multirow[t]{6}{*}{ Age group } & $<28$ days & 1 & 1 & 1 \\
\hline & 1-2 months & $0 \cdot 18(0 \cdot 14-0 \cdot 23)$ & $0 \cdot 18(0 \cdot 14-0 \cdot 23)$ & $0 \cdot 18(0 \cdot 14-0 \cdot 23)$ \\
\hline & 3-11 months & $0 \cdot 10(0 \cdot 08-0 \cdot 12)$ & $0 \cdot 10(0 \cdot 08-0 \cdot 12)$ & $0 \cdot 10(0 \cdot 08-0 \cdot 12)$ \\
\hline & 1 year & $0.04(0.03-0.05)$ & $0.04(0.03-0.05)$ & $0.04(0.03-0.05)$ \\
\hline & 2 years & $0.02(0 \cdot 01-0 \cdot 03)$ & $0.02(0.01-0.03)$ & $0.02(0.01-0.03)$ \\
\hline & $3-4$ years & $0.01(0 \cdot 00-0 \cdot 01)$ & $0 \cdot 01(0 \cdot 00-0 \cdot 01)$ & $0 \cdot 01(0 \cdot 00-0 \cdot 01)$ \\
\hline $\begin{array}{l}\text { Population group } \\
\text { by age group }\end{array}$ & $\begin{array}{l}\text { Non-African groups } \\
\text { at } 1+\text { months }\end{array}$ & $0 \cdot 49(0 \cdot 30-0 \cdot 82)$ & $0.49(0.30-0.82)$ & $0.49(0.30-0 \cdot 82)$ \\
\hline \multirow[t]{2}{*}{ Residence } & Metropolitan & & 1 & 1 \\
\hline & Non-metropolitan & & $1 \cdot 29(1 \cdot 08-1 \cdot 55)$ & $1 \cdot 17(0 \cdot 97-1 \cdot 40)$ \\
\hline \multirow[t]{9}{*}{ Province } & Eastern Cape & & 1 & 1 \\
\hline & Mpumalanga & & $0.93(0 \cdot 76-1 \cdot 14)$ & $0.92(0 \cdot 75-1 \cdot 12)$ \\
\hline & KwaZulu Natal & & $0.90(0 \cdot 70-1 \cdot 15)$ & $0.87(0.69-1 \cdot 10)$ \\
\hline & Northern Cape & & $0 \cdot 81(0 \cdot 58-1 \cdot 12)$ & $0.76(0.55-1.06)$ \\
\hline & Gauteng & & $0.75(0.55-1.02)$ & $0.74(0.54-1.01)$ \\
\hline & North West & & $0.68(0.50-0.91)$ & $0.68(0.51-0.92)$ \\
\hline & Free State & & $0.65(0.51-0.83)$ & $0.64(0.50-0.81)$ \\
\hline & Limpopo & & $0.60(0.46-0.78)$ & $0.60(0.46-0.78)$ \\
\hline & Western Cape & & $0 \cdot 32(0 \cdot 20-0 \cdot 52)$ & $0 \cdot 30(0 \cdot 19-0 \cdot 49)$ \\
\hline \multirow{3}{*}{\multicolumn{2}{|c|}{$\begin{array}{c}\text { Mother's education None or primary } \\
\text { Some secondary } \\
\text { Matriculation or } \\
\text { above }\end{array}$}} & & & 1 \\
\hline & & & & $0.77(0.66-0.91)$ \\
\hline & & & & $0.57(0.43-0.74)$ \\
\hline
\end{tabular}


Table 4. Relative risk of dying by population group and age: Model 1

\begin{tabular}{lcccc}
\hline Age group & African & Coloured & Asian & White \\
\hline$<28$ days & 1 & $0 \cdot 759$ & $0 \cdot 711$ & $0 \cdot 309$ \\
1-2 months & $0 \cdot 177$ & $0 \cdot 066$ & $0 \cdot 062$ & $0 \cdot 027$ \\
3-11 months & $0 \cdot 097$ & $0 \cdot 036$ & $0 \cdot 034$ & $0 \cdot 015$ \\
1 year & $0 \cdot 039$ & $0 \cdot 014$ & $0 \cdot 014$ & $0 \cdot 006$ \\
2 years & $0 \cdot 019$ & $0 \cdot 007$ & $0 \cdot 007$ & $0 \cdot 003$ \\
3-4 years & $0 \cdot 006$ & $0 \cdot 002$ & $0 \cdot 002$ & $0 \cdot 001$ \\
\hline
\end{tabular}

an artefact of poor data quality. In general, although where children live is important in its own right, it does not seem to be of major importance in accounting for racial differences in under-five mortality in South Africa.

The final model further controls for variations in mothers' education. Compared with mothers with no education or only primary schooling, the mortality risk of children whose mothers have a secondary education is reduced by $23 \%$, while children born to women who have matriculated or progressed to post-school education are $57 \%$ as likely to die. Both ratios are highly significant. Controlling for education halves the beneficial effect of metropolitan residence and leaves it insignificant $(p=0.095)$, suggesting that much of the advantage of metropolitan areas in South Africa is accounted for by the composition of the population of such areas rather than by better service provision. While relatively high levels of maternal education account for some of the mortality advantage of Asian and White children, lack of schooling is only a minor explanation of the high mortality of children of African women. The attenuation of the decline over time in mortality between Model 2 and Model 3 suggests that improvements in women's education are associated with about $15 \%$ of the reduction in under-five mortality between the early 1980s and 1992-95.

\section{Discussion}

This paper investigates levels, patterns and covariates of child mortality in South Africa during a period when HIV infection began to have an effect on mortality and when the political transition began to steer health and social policy in a new direction.

The first major issue raised by the 1996 Census and 1998 DHS estimates of childhood mortality is that the unadjusted Census results are about $50 \%$ higher than those from the DHS. Faced with such discrepancies, most demographers accustomed to working with developing country data would assume that the higher estimates are more likely to be accurate. However, in general, direct estimates from DHS surveys only slightly underestimate the true mortality rate, mainly due to omissions of dead children (Sullivan et al., 1990). We argue that this is true of South Africa. Although a degree of bias in the DHS sample and some under-reporting of deaths in Western Cape and Free State do lead the DHS to underestimate childhood mortality, much of the problem is with the Census results. 
The most important explanation of the discrepancy between the DHS and Census results is likely to be misreporting of stillbirths as live births (Moultrie \& Timæus, 2002). We have argued that is unlikely that the DHS interviewers collected complete information on surviving children and information on large numbers of abortions and stillbirths yet failed to record a large proportion of children who have died. In the absence of a gold standard against which to assess both sets of data, it is impossible to prove this. However, given the confused phrasing of the Census question and much higher standard of interviewer training and quality control procedures in the DHS, it is more likely that pregnancy outcomes were misclassified in the Census than that substantial numbers of dead children went unreported in the survey.

Misreporting of stillbirths as dead live births is a potential reporting bias in retrospective survey data on developing countries that has not received much attention in the literature. It could be an important problem leading to overestimation of infant mortality in countries other than South Africa. The actual stillbirth ratio in South Africa is certainly higher than the 14.5 per 1000 live births reported in the DHS. For example, Louw et al. (1995) report that the stillbirth rate in 1989-91 in Cape Province was 18 per 1000 for births occurring in hospital. Based on historical data from Europe, Woods (2005) argues that the stillbirth rate in populations that lack access to modern health care usually lies in the range 25-60 per 1000 live births. While one would expect the stillbirth rate to be associated with infant mortality, it varies less between populations. Therefore, in a high-mortality population with, for example, an infant mortality rate of 150 per 1000 and under-five mortality of 250 per 1000 , reporting of a fraction of stillbirths as dead live births will introduce only a moderate upward bias into estimates of childhood mortality. This may be offset or overwhelmed by biases operating in the other direction. In contrast, in middle-income countries such as South Africa, where the infant mortality rate dropped to about 40 per 1000 and under-five mortality to about 50 per 1000 in the early 1990 s, reporting of a significant proportion of stillbirths as dead live births can introduce a substantial upward bias into survey-based estimates of childhood mortality.

Application of the indirect method to the 1998 DHS data and comparison of the results with those calculated directly from the pregnancy histories reveals that the former are too high. The discrepancy is sufficiently large and reflects so much of the total exposure by age and time reported in the DHS histories that it cannot be explained by misreporting of ages and dates of death. Although the indirect estimation procedure is usually rather insensitive to breaches in its assumptions, the bias in these estimates must originate with the procedure, not the data. The demography of South Africa has one unusual and marked feature that can account for this problem: birth intervals have been rising steadily since about 1970 and are now extraordinarily long (Moultrie \& Timæus, 2002). For example, Greene (1998) found that the median birth interval in the five years prior to thirteen DHS surveys conducted in sub-Saharan Africa in the early 1990s averaged 32 months. In South Africa the equivalent statistic is 59 months! The implication of this is that mothers in each age group have children who are older than is usual. The proportion of them that have died is equivalent to life-table survivorship to a markedly older age than that with which it is equated during indirect estimation. As a result, the indirect estimates of children's mortality are too high. 
Turning to mortality trends, one assumption of the indirect method of estimating childhood mortality is homogeneity of mortality risk by age of the mother. The problem of upward bias in indirect estimates of mortality based on the children of respondents aged 15-19 has been recognized for some time. Fernandez (1989) investigated the relationship between mortality and age of mother, parity and birth interval and shows that the higher mortality of births to teenage mothers may bias up the second point representing the mortality experience of the children born to 20- to 24-year-old mothers as well as the most recent point based on the reports of teenaged girls themselves. South Africa has high rates of adolescent fertility with almost one-sixth of all births occurring to women in their teenage years (Department of Health, 2002), so the effect of differential risk as a function of maternal age is likely to be substantial. It is therefore important to determine whether the apparent upturn in childhood mortality revealed by the indirect estimates is real or an artefact of the methodology.

In this paper an adjustment proposed by Collumbien \& Sloggett (2001) is adopted that uses supplementary country-specific data to correct the indirect estimates for the two youngest age groups of mothers. Doing so reduces the size of the estimated increase in under-five mortality in the period immediately before the data were collected, but fails to alter the conclusion that the decline in childhood mortality first halted and was then reversed in the early 1990s (Fig. 1). The Census estimates suggest that the rise in mortality is somewhat less than that recorded in the most recent direct estimates from the DHS but this is partly because of the inbuilt tendency for cohort measures to smooth out sharp fluctuations in mortality and partly because the DHS data are two years more up-to-date. Given that the adjusted Census results follow a very similar time trend to the indirect estimates from the DHS, they are entirely consistent with the finding that childhood mortality rose substantially in South Africa in the mid-1990s. Our argument is that, although the 1998 DHS data may slightly underestimate the level of mortality in childhood in South Africa, the 1996 Census data support the evidence that the DHS provides as to mortality trends. Gains were being made up until 1992, after which infant and child mortality rose (Fig. 1). The unadjusted DHS estimates may require inflating by about $5 \%$ but suggest that infant mortality increased from 38 per 1000 in 1992 to 52 per 1000 early in 1998, while child mortality began to increase slightly afterwards, rising from about 12 per 1000 in 1995 to 17 per 1000 less than three years later. The regression analysis confirms that this increase is statistically significant.

African neonates are more than three times as likely to die as White babies of the same age. During the rest of their early childhood they are 6.6 times more likely to die than White children and also have significantly higher mortality than Asian and Coloured children (Model 1). Only some of this differential is accounted for by where the different population groups live and the differential education of mothers. After controlling for these factors, African children have $4 \cdot 1$ times the mortality of White children after the first month of life (Model 3). While the exact mechanisms involved in this differential are unclear, place and schooling have been controlled for and the major underlying factor involved is without doubt poverty. In recent decades, a wealth of research has documented relationships between health and socioeconomic status in the developing world (Hobcraft et al., 1985; Cebu Study Team, 1991; 
Cleland et al., 1992; Hobcraft, 1993). The striking differences in child mortality between population groups in South Africa are a clear indication of the continuing impact of apartheid policies on the socioeconomic gradient according to racial classification.

In comparison with the results of the HSRC surveys, our findings support the suggestion made on the basis of the 1996 Census data that absolute and relative differences in childhood mortality between the population groups have narrowed over time (Bradshaw et al., 2000). Older data suggest that in 1935, the Coloured infant mortality rate was 6 times higher than for White infants (Wyndham \& Irwig, 1979). Moreover, even in the first half of the 1980s, Yach (1988) reported urban mortality rates that were 9-10 times higher for African children and 4 times higher for Coloured children than they were for White children. Burgard \& Trieman (2006) also observe that the difference between the infant mortality of Whites compared with Africans has shrunk, although this trend was not statistically significant in their analysis.

It is evident from the HRSC surveys (Rossouw \& Jordaan, 1997) that place of residence was a strong determinant of child mortality in the 1980s. These surveys documented large variations in infant mortality rates between areas that were homelands, rural and less developed and areas that were more urbanized and developed. The 1998 DHS data show that the Western Cape, Limpopo, Free State, North West and Gauteng provinces have lower child mortality than the Eastern Cape, Mpumalanga and KwaZulu-Natal. To some extent this provincial patterning still reflects past disadvantages experienced by children in the impoverished areas that did not fall within the White republic under apartheid. These continued provincial inequalities are also borne out in socioeconomic indicators such as household income (Statistics South Africa, 2000), levels of formal education and levels of unemployment (Statistics South Africa, 2003).

Having said this, it is clear that provincial differences in mortality in South Africa are not solely a product of the country's apartheid history. As Yach (1988) notes, large differences in childhood mortality existed between the homelands before 1994. Venda, Bophuthatswana and Ciskei had infant mortality rates as low as $36-41$, compared with 130 in the Transkei. Today, after controlling for other factors, a broad east-west differential in the level of child mortality in the country is apparent. In addition childhood mortality appears quite low in the poorly developed Limpopo province. While it is possible that this in part reflects poor reporting of child deaths, successive inquiries have replicated this finding. For example, the HSRC surveys found that mortality was fairly low in this part of the country but also emphasize that marked differences existed between smaller areas now incorporated into this province: childhood mortality was about $20 \%$ lower in Gazankulu than Lebowa (Rossouw \& Jordaan, 1997). Thus, to gain any deeper understanding of the geography of infant and child mortality in South Africa would require data on smaller areas than provinces. This is not a line of inquiry that can be pursued with a survey the size of the DHS.

In a comparative analysis of DHS data, Rutstein (2000) divided the determinants of early-age mortality into five groups of explanatory variables: fertility behaviour, nutritional status and infant feeding, the use of health services by mothers and children, environmental health conditions and socioeconomic factors. His paper 
concludes that the ongoing declines and reversals in childhood mortality that occurred in the developing world in the 1990s involved a range of these variables. Changes in fertility behaviour are likely to have had an impact on childhood mortality due to the extensive and strong family planning services established in 1974 (Klugman, 1994) in South Africa. Fertility has fallen and short birth intervals have become rarer, although teenage pregnancies remain common. Changes have also occurred both before and since 1994 in socioeconomic and environmental conditions and the use of health services by mothers and children. Our results show that rising educational levels of women account for part of the reduction in childhood mortality in South Africa in the 1980s. However, it is probably now impossible to determine either the mechanisms involved in this educational effect or the contribution of rising incomes, health care provision and use and related factors to past mortality trends given the inadequacy of health information systems and widespread resource inequities in the apartheid years (Yach et al., 1987).

It is known that, while curative health care in South Africa is undoubtedly better than in most countries to its north, indicators of prevention such as the prevalence of breast-feeding and immunization coverage have shown little improvement over the last 20 years (Department of Health, 2002). Although apartheid South Africa never officially committed to 'Health for All' by the year 2000 (World Health Organization, 1978), there were initiatives to implement selected primary health care approaches including growth monitoring, oral rehydration, breast-feeding and immunization (Mosley \& Chen, 1984). It is likely that implementation of these was uneven across the country and it is unclear what impact preventive care may have had on mortality trends.

Extrapolation of the downward trend in under-five mortality prior to 1990 forward to the end of 1997 produces a predicted under-five mortality rate of 35 per 1000, half our estimate of 72 per 1000. Close inspection of Figure 2 suggests that for infants, if not older children, stagnation of mortality decline dates back to the late 1980s and predates the demise of the apartheid regime. This raises the question of whether the adverse trends in childhood during the 1990s resulted entirely from the rapid increase in HIV prevalence rates or whether reversal of the previous decline also reflected the immense upheaval that took place during the decade in the health services (Benatar, 2004) and society at large. To attempt to resolve this issue one can use the surveillance data on the prevalence of HIV infection in pregnant women (Department of Health South Africa, 2005, and earlier annual reports in this series) to estimate the impact of AIDS on childhood mortality a couple of years later. It is assumed that, given the limited therapy available to HIV-positive women during pregnancy in South Africa in the 1990s, one-third of infected women transmitted the virus to their children and that $60 \%$ of infected children die before the age of five (Marston et al., 2005). For example, an HIV prevalence rate of $10 \%$ among pregnant women would be expected to produce an under-five mortality rate two years later that is about 20 per thousand higher than would have been observed in the absence of AIDS. (Adjusting for competing risks makes little difference to these estimates and is not really justified given the crudity of this calculation.) On this basis, it is estimated that AIDS mortality explains about two-thirds of excess child deaths above the previous trend in South Africa in 1992 to 1997. This result suggests that, even in the 
absence of an HIV/AIDS epidemic, under-five mortality might have continued to stagnate for most of the 1990s at about the level of 50 per 1000 that it had reached by the end of the 1980s. The actual rise in childhood mortality in the 1990s, in contrast, can plausibly be accounted for by AIDS.

\section{Conclusion}

Despite its unique history, South Africa benefited from a major drop in infant and child mortality between the 1970s and early 1990s like that seen in most other lowand middle-income countries. The biggest reductions in childhood mortality occurred in the 1975-85 decade and the post-neonatal and 1-4 year age groups benefited more than neonates. Unfortunately, South Africa is also among a number of countries that have since seen a reversal in the trend in mortality linked to deaths from AIDS (Adetunji, 2000). The 1996 Census and the 1998 DHS data confirm that childhood mortality rose in South Africa during the 1990s. Under-five mortality increased by about a third during the five years to early 1998. By this date the infant mortality rate was about 55 per 1000 and under-five mortality was 72 per 1000 . While other factors may explain the tapering off of mortality decline from the late 1980s on, deaths from AIDS account for most of the increase.

This analysis emphasizes the continuing importance of racial disparities in child survival which have their origins in the inequalities created by apartheid policies. Population groups and areas that were discriminated against before 1994 still face social and economic disadvantages which have direct and indirect effects on health. Racial inequalities in childhood mortality have narrowed in absolute and relative terms over the last 20 years. Nevertheless, the legacy of apartheid continues to affect provincial as well as inter-group mortality differentials and these inequalities are likely to persist for many years. Because the African population is worst affected, the HIV/AIDS epidemic is likely to offset the beneficial impact of pro-poor policies and may exacerbate racial differences in childhood mortality in South Africa.

It has been proposed that 'socioeconomic status gaps in child mortality are not simply inequalities, they are also inequities - inequalities that are unjust and unfair' (Victora et al., 2003). Given South Africa's past, ensuring equity is a key issue in the development of health and related social development policy. Although the prevention of mother-to-child transmission of HIV is the single most effective intervention directed at reducing under-five mortality in South Africa, it remains important to develop an integrated approach to efforts to improve the health status of children by improving the education of women, providing clean water, sanitation and safe environments, and ensuring equitable access to primary health care.

It is extremely worrying that the health information system in South Africa remains inadequate for monitoring levels of and trends in infant and child mortality. The 1998 DHS data are now severely out of date but, because of the failure of the 2001 Census to yield useful estimates, provide the most recent soundly based estimates available for the country as a whole. Thus, it is uncertain whether infant and child mortality have continued to rise since 1998 or what their level is currently. It is impossible to monitor progress in South Africa towards the Millennium Development Goals of reducing child mortality and improving child health or to investigate what 
factors are shaping trends in childhood mortality nationally. One continuing priority for action remains the improvement of the coverage and timeliness of registration and statistical reporting of births and child deaths. In addition, a strong case exists for prioritizing the collection of information on childhood mortality as a routine and integral component of the government's programme of household surveys. Such surveys must be adequately resourced, benefit from strong technical and managerial support, and avoid being over-ambitious in either their objectives or scale.

\section{References}

Adetunji, J. (2000) Trends in under-5 mortality rates and the HIV/AIDS epidemic. Bulletin of the World Health Organization 78(10), 1172-1282.

Bachmann, M., London, L. \& Barron, P. (1996) Infant mortality rate inequalities in the Western Cape province of South Africa. International Journal of Epidemiology 25(5), 966-972.

Benatar, S. R. (2004) Health care reform and the crisis of HIV and AIDS in South Africa. New England Journal of Medicine 351(1), 81-92.

Botha, J. L. \& Bradshaw, D. (1985) African vital statistics -a black hole? South African Medical Journal 67(24), 977-981.

Bradshaw, D., Masiteng, K. \& Nannan, N. (2000) Health status and determinants. In South African Health Review 2000. Health Systems Trust 2000, pp. 89-124.

Bradshaw, D. \& Nannan, N. (2004) Health Status. In South African Health Review 2003/04. Health Systems Trust 2004, pp. 45-56.

Brass, W. \& Coale, A. J. (1968) Methods of analysis and estimation. In Brass, W., Coale, A. J., Demeny, P., Heisel, D. F., Lorimer, F., Romaniuk, A. \& van de Walle, E. (eds) The Demography of Tropical Africa. Princeton University Press, pp. 88-139.

Burgard, S. A. \& Treiman, D. J. (2006) Trends and racial differences in infant mortality in South Africa. Social Science and Medicine 62(5), 1126-1137.

Case, A. \& Deaton, A. (1998) Large cash transfers to the elderly in South Africa. Economic Journal 108(450), 1330-1361.

Cebu Study Team (1991) Underlying and proximate determinants of child health: the Cebu Longitudinal Health and Nutrition Study. American Journal of Epidemiology 133, 185-201.

Cleland J., Bicego, G. \& Fegan, G. (1992) Socioeconomic inequalities in childhood mortality: the 1970s to the 1980s. Health Transition Review 2(1), 1-18.

Coale, A. J., Demeny, P. \& Vaughan, B. (1983) Regional Model Life Tables and Stable Population ( $2^{\text {nd }}$ edn). Academic Press, New York.

Collumbien, M. \& Sloggett, A. (2001) Adjustment methods for bias in the indirect childhood mortality estimates. In Zaba, B. \& Blacker, J. (eds) Brass Tacks. Essays in Medical Demography. Athlone Press, pp. 21-42.

Department of Health, South Africa (2002) South Africa Demographic and Health Survey 1998. Full Report. Department of Health, Pretoria.

Department of Health, South Africa (2005) National HIV and Syphilis Antenatal Survey in South Africa 2004. Department of Health, Pretoria.

Dorrington, R., Moultrie, T. A. \& Timæus, I. M. (2004) Estimation of Mortality using the South African Census 2001 Data. Monograph 11. Centre for Actuarial Research, University of Cape Town, Cape Town.

El-Badry, M. A. (1961) Failure of enumerators to make entries of zero errors in recording childless cases in population censuses. Journal of the American Statistical Association 56(296), 909-924. 
Fernandez Castilla, R. (1989) The effects of maternal age, birth order and birth spacing on indirect estimation of child mortality. International Population Conference, New Delhi. International Union for the Scientific Study of Population, Liege, pp. 65-86.

Greene, M. L. (1998) Contraceptive use for birth spacing in sub-Saharan Africa. PhD dissertation, Princeton University, NJ.

Henderson, R. (1916). Note on graduation by adjusted average. Transactions of the American Society of Actuaries 17, 43-48.

Hobcraft, J. (1993). Women's education, child welfare and child survival: a review of the evidence. Health Transition Review 3(2), 159-175.

Hobcraft, J., McDonald, J. \& Rutstein, S. (1985) Demographic determinants of infant and early child mortality: a comparative analysis. Population Studies 39(3), 363-385.

Klugman, B. (1994) Population Policy in South Africa: Where to From Here? Policy Working Paper No. 31. Development Bank of Southern Africa, Midrand.

Louw, H. H., Khan, M. B., Woods, D. L., Power, M. \& Thompson M. C. (1995) Perinatal mortality in the Cape Province, 1989-1991. South African Journal of Medicine 85(5), 352-355.

Marston, M., Zaba, B., Salomon, J. A., Brahmbhatt, H. \& Bagenda, D. (2005) Estimating the net effect of HIV on child mortality in African populations affected by generalized HIV epidemics. Journal of Acquired Immune Deficiency Syndromes 38(2), 219-227.

Mazur, R. E. (1995) Population Structure, Fertility and Childhood Mortality in South Africa: Lessons to be Learned from Analysis of the Poverty Survey. Centre for Epidemiological Research in Southern Africa, Medical Research Council, South Africa.

Mosley, H. W. \& Chen, L. C. (1984). An analytical framework for the study of child survival in developing countries. Population and Development Review 10 (supplement), 25-45.

Moultrie, T. A. \& Timæus, I. M. (2002) Trends in South African Fertility between 1970 and 1998: An Analysis of the 1996 Census and the 1998 Demographic and Health Survey. Burden of Disease Research Unit Technical Report. Medical Research Council, South Africa, pp. x+81. http://www.mrc.ac.za/researchreports/trends.pdf.

Moultrie, T. A. \& Timæus, I. M. (2003) The South African fertility decline: evidence from two censuses and a Demographic and Fertility Survey. Population Studies 57(3), 265-283.

Nannan, N., Bradshaw, D., Mazur, R. \& Maphumalo, S. (1998) What is the infant mortality rate in South Africa? The need for improved data. South African Medical Journal 88(12), 1583-1587.

Pick, W. M., Bourne, D. E. \& Sayed, A. R. (1996) Race, income and infant mortality in Cape Town, South Africa. Journal of Tropical Pediatrics 42(4), 250-251.

Rossouw, J. P. H. \& Hofmeyr, B. E. (1990) Infant and child mortality in South Africa: Levels, differentials and determinants. In Mostert, W. P. \& Lotter, J. M. (eds) South Africa's Demographic Future. Human Science Research Council, Pretoria, pp. 34-44.

Rossouw, J. P. H. \& Jordaan, A. (1997) Infant Mortality and Child Health in South Africa 1988-1992: Findings from a Series of Demographic and Health Surveys. Human Sciences Research Council, Pretoria.

Rutstein, S. O. (2000) Factors associated with trends in infant and child mortality in developing countries during the 1990s. Bulletin of the World Health Organization 78(10), 1256-1270.

STATA Corp (2005a) Survival Analysis and Epidemiological Tables Reference Manual. STATA Corporation, College Station, TX.

STATA Corp (2005b) Survey Data Reference Manual. STATA Corporation, College Station, TX.

Statistics South Africa (2000) Measuring Poverty. Statistics South Africa, Pretoria.

Statistics South Africa (2003) Census 2001: Census in Brief. Report No. 03-02-03 (2001). Statistics South Africa, Pretoria. 
Sullivan, J. M., Bicego, G. T. \& Rutstein, S. O. (1990) Assessment of the quality of data used for the direct estimation of infant and child mortality in the Demographic and Health Surveys. In An Assessment of DHS-I Data Quality. Demographic and Health Surveys Methodological Reports No. 1. Institute for Resource Development/Macro Systems Inc., Columbia, MD, pp. 113-143.

Terreblanche, S. (2003) A History of Inequality in South Africa, 1652-2002 (Chapter 2). University of Natal Press, Pietermaritzburg, pp. 25-49.

Treiman, D. J., Mckeever, M. \& Fodor, E. (1996) Racial differences in occupational status and income in South Africa, 1980 and 1991. Demography 33(1), 111-132.

United Nations (1983) Manual X: Indirect Techniques for Demographic Estimation (Chapter 3). United Nations, New York.

United Nations (2000) Millennium Development Goals. http://www.who.int/mdg/goals/en/ (accessed 7th May 2006).

United Nations Development Program (2001) Human Development Report, South Africa. Oxford University Press, New York.

Victora, C. G., Wagstaff, A., Armstrong Schellenberg, J., Gwatkin, D., Claeson, M. \& Habicht, J-P. (2003) Applying an equity lens to child health and mortality: more of the same is not enough. Lancet 362, 233-241.

Woods, R. (2005) The measurement of historical trends in fetal mortality in England and Wales. Population Studies 59(2), 147-162.

World Health Organization (1978) Report of the International Conference on Primary Health Care. Alma-Ata, Sept 6th-12th World Health Organization, Geneva.

World Health Organization (1983) Apartheid and Health. World Health Organization, Geneva.

Wyndham, C. H. (1981) The loss from premature deaths of economically active manpower in the various populations of the RSA. South African Medical Journal 60(12), 411-419.

Wyndham, C. H. \& Irwig, L. M. (1979) A comparison of the mortality rates of various population groups in the Republic of South Africa. South African Medical Journal 55(20), 796-802.

Yach, D. (1988) Infant mortality rates in urban areas of South Africa, 1981-1985. South African Medical Journal 73(4), 232-234.

Yach, D., Klopper, J. M. \& Taylor, S. P. (1987) Use of indicators in achieving 'Health for All' in South Africa, 1987. South African Medical Journal 72(11), 805-807. 